\title{
E-Learning Strategies in Technical Part-Time Studies at Campus Pinkafeld: A Moderate Constructivist Approach to Learning and Teaching
}

\author{
$\underline{\text { doi:10.3991/ijac.v2i1.800 }}$ \\ A. Kelz \\ University of Applied Sciences Burgenland, Campus Pinkafeld, Austria
}

\begin{abstract}
The introduction of part-time studies contributed decisively to a wider acceptance of technical degree programmes at Campus Pinkafeld as their particular organisational design allows students to study alongside work and family commitments. As far as higher technical education is concerned, they provide constructivist-oriented pedagogic approaches to best prepare students for the workplace. In contrast to traditional behaviourist notions, constructivist frameworks allow for blended-learning settings which help implement learning scenarios based on open, technology-aided, learner-centred, self-directed and collaborative learning environments. Exploring some of these more progressive, process-oriented approaches to learning and teaching and the theory behind it are the primary aims of this paper.
\end{abstract}

Index Terms-Blended learning, collaborative learning environments, constructivism, technical education, parttime studies.

\section{INTRODUCTION}

In line with the principles of the treaty of Bologna to converge higher educational systems towards a more transparent system, a re-organisation of the key area of study Energy and Environmental Management at Campus Pinkafeld started in 2004 to transform all 4-year diploma programmes into Bachelor's and Master's degree programmes. Since then Campus Pinkafeld has been offering part-time degree courses using the "blended learning approach”, allowing for a combination of on-site and off-campus study modules. Thus students are provided the flexibility in attaining their higher education while working full or part-time and/or having to overcome long distances to get to the campus in Pinkafeld.

In order to successfully implement part-time Bachelor's and Master's programmes the studies offered in Pinkafeld had to be tailored to suit the particular needs of the target groups. First, new organisational designs were needed to allow students to study alongside work and family commitments. Second, a new constructivist-based didactic framework and its corresponding teaching methods and learning strategies had to be established to help the students acquire the relevant skills and competences for their future field of work. Both objectives could be achieved by technology-aided blended learning settings. They allow for a considerable reduction of f2 $\mathrm{f}$ sessions and help implement new learning scenarios which are based on open, computer-aided, learner-centred, selfdirected and collaborative learning arrangements.

\section{A SHIFT IN LEARNING PARADIGMS}

Providing workplace skills and knowledge is a fundamental task for higher technical education. On the one hand there is a base set of currently accepted knowledge and skills that graduates need to understand and perform today, on the other hand they must be prepared to adapt to the knowledge and skills that will be needed in the future. Hence, the goal of technical education must be occupationally self-regulated individuals who do not only have a core set of essential domain-specific knowledge and skills but are also able to continuously adapt to new technologies and workplace skills. It also needs to be stated that there has been a move toward competency or outcomes-based programmes of study 'with clearly defined, concrete, measurable objectives of which every student participating in the program must have demonstrated mastery upon program completion' [1]. The curriculum of such competencybased programmes relies on pre-determined performance objectives which are structured from the perspective of industry needs and standards [2]. In adult technical education this trend toward competency-based education is viewed as beneficial for reasons of global standardization which allows for more equitable matching of technical education and training with on-the-job needs [3].

The dominant model for the pedagogy of the competency-based curriculum of technical programmes is still based on the behaviourist learning and teaching approach which assumes that learning is related to creating associations between stimuli provided by the environment (teacher) and responses developed by individuals (learners). The nature of employability and workplace skills, however, has changed from simple repetitive tasks to complex, problem-solving and collaborative tasks and therefore students need to be provided the technical skills and knowledge necessary to have the chance to succeed in various technical occupations. As the behaviourist conceptual framework no longer complies with the demand for learning environments that foster self-directed and collaborative learning, a new learning theory is needed and it has been 
shown that constructivism can provide a viable theoretical framework for the pedagogy and curriculum of technical education at university level.

\section{CONSTRUCTIVISM}

In order to adequately prepare students to successfully enter the workplace a broad change in the philosophical orientation of higher technical education away from behaviourism and toward constructivism has been going on for some time. This fundamental change concerns the assumptions underlying the pedagogy and curriculum of technical education and implies a rethinking of how we determine, structure and deliver the content of technical education and try to find ways to restructure the overall learning environment so that it will make transfer more effective.

Traditional learning and teaching is mainly based on behaviourist notions (learning as the acquisition of stimulus-response pairs) and cognitive assumptions (learning as the processing of information). It is thus mainly teacher-centred, which means that students passively receive information and are told what to do in order to fulfil the requirements of the university. The technical education requirement of students learning a core set of reliable knowledge and skills is still valid, but the learning process itself has gained in importance as it has become to be seen as the most essential part of education. According to the constructivist view of learning we are active creators of our own knowledge, i. e. we don't passively receive information but construct our own understanding and knowledge of the world through experiencing things, reflecting on and examining those experiences, linking all new information gained from this reflection and examination to existing knowledge and eventually integrating those new experiences into our existing mental constructs. In terms of students this means that they actively construct their own meanings and understandings rather than passively absorb knowledge transmitted by a lecturer or textbook. Hence, one of the lecturer's main roles becomes to encourage this learning and reflection process. Within such a teaching and learning framework students should become selfregulatory and approach the ultimate goal of becoming autonomous, life-long learners.

\section{A. Basic Principles of Constructivist Learning and Teaching}

Basic design principles of constructivist learning and teaching environments found in various literature and articles such as "Constructivism: The Career and Technical Education Perspective” [4] might be briefly summarized as follows:

- Provide authentic, real-world, motivating, open learning environments, taking into account appropriate methods, techniques, learning material and media as well as the socio-cultural context and the situation of learning.

- Pose real problems on which students can work. Focus on content and skills which are relevant to the students. They need to understand the relevancy of certain knowledge and skills as it is likely to lead to an increase in learner motivation.
- Focus on realistic approaches to solving real-world problems to help students develop domain-specific problem-solving strategies. Design problem-based learning activities, use case studies, project-work, exploration tasks etc. to encourage students to seek knowledge independently.

- Consider the students' previous knowledge, beliefs and attitudes in the knowledge construction process. Depending on students' prior experience, related cases and scaffolding, a process of guiding students from what they presently know to what is to be known, may be necessary for support.

- Provide and encourage interdisciplinary and holistic approaches as well as multiple perspectives and representations of content.

- Encourage social interaction as it provides for the development of socially relevant skills and knowledge. Collaborative learning enlivens and enriches the learning process through sharing and exchanging information and thus coming to new insights and understanding.

- Leave enough room for all kinds of feedback.

- Continually assess the learners' progress. Assessment should be authentic and interwoven with teaching.

- Serve primarily as guide, coach and facilitator of learning, not instructor. Don't try to transmit knowledge pedantically but provide students with opportunities and incentives to build it up. Motivate, support and challenge the students, provide relevant information and examples, discuss questions, problems, solutions etc.

- Allow students to actively engage in the learning process (choice of didactics, content, activities, learning and teaching methods etc.) as they should be co-producers of their own learning.

- Encourage self-awareness in the knowledge construction process. Students should identify, pursue and reflect on their own learning goals and strategies. They should learn to take ownership of their own learning as learning is a continuous, lifelong process.

\section{B. Collaboration}

Today, employers expect more from graduates than simple entry-level job skills - they ask for generalized skills as they must be ready to solve complex problems, exhibit self-directed, self-assessing behaviour on the job and function in collaborative settings. In order to be prepared for such settings, students need to be encouraged to cooperate and collaborate on authentic assignments which provide a realistic, cognitively motivating and socially enriched learning context to support the learning process. Collaborative learning is a student-centred approach that requires students working together to accomplish a shared learning goal and to maximize their own and their group members' achievements. In a collaborative learning environment the students are challenged both cognitively and socially as they listen to different perspectives from students with varied backgrounds and are required to articulate and defend their ideas or to participate in group decision-making processes. As collaborative activities play a major role in 
the constructive, cognitive development of the students they fit in well with the constructivist approach.

\section{WEB-BASED LEARNING ENVIRONMENTS}

Constructivism, learning and technology are increasingly linked by researchers and educators as many see strong support for the principles of constructivist philosophy in web-based learning environments. Various learning management systems are used to accommodate constructivist theory of learning in educational practice and to provide students with tools for learning, communication, and collaboration. The Internet and the various learning management systems have diversified the opportunities for lecturers by varying and broadening the alternatives for learning and teaching. This requires reconsidering the pedagogy and methodology of teaching which again paves the way for collaborative learning environments.

\section{A. Learning Management Systems}

A web-based learning environment usually implies a learning management system that allows certain learning processes. Such platforms are designed on the basis of different didactic concepts mainly with the intention to arrange online courses or a combination of online and face-to-face teaching (blended learning). The technological framework becomes a central point of a virtual learning environment as it is the basis for communication and collaboration, transfer of information and the presentation of study material. Each learning manangement system can be used to basically support three types of learning, which are learning from information through distribution, learning from feedback through interaction and learning from different perspectives through collaboration [5]. Depending on the different types of courses and their specific objectives and contents the platform is either used to distribute relevant information or to support interaction and collaboration of any kind. It offers improved ways of distributing information (presenting, researching, documenting), supporting communication (interaction, collaboration) and enhancing cognition (visualizing, animating, simulating).

Web-based learning environments are becoming increasingly popular in higher technical education as both students and lecturers gain benefits from such scenarios. Among the many well-known benefits for adult learners of part-time studies there are some still worth mentioning. They do not only increase interaction among students with web-based communication tools that permit group work that would be difficult to arrange if students had to meet in the same physical location at the same time, they also provide adult students, who tend to be highly-motivated learners, with the ability to actively pursue areas of greatest interest, rather than sitting through courses developed for a broad range of students. They also embrace the lecturer's change from role of an instructor to role of a coach who, taking into account their professional experiences, can lead students to get out of the course what will be most valuable to them.

Despite its advantages, technology itself doesn't necessarily promote learning. Apart from appropriate learning objectives and pedagogical strategies it is of high importance how software tools are adapted in the learning process. The important thing is to take advantage of the technology to improve the efficiency of learning. Effective online learning requires more commitment from the teaching staff and much more student self-discipline and motivation than traditional f2f teaching.

\section{B. Blended Learning Scenarios}

The pedagogic design of technical part-time studies helps implement new blended learning scenarios which are based on open, computer-aided, learner-centred, selfdirected and collaborative learning environments. Even though blended learning has become somewhat of a buzzword in education settings, there still is some ambiguity about what is really meant by the term. Generally, blended or hybrid learning is the term used to describe learning activities based on a combination of f2f with online learning settings, using a variety of teaching approaches and media.

The question to be answered is how we can make use of a mixed setting of blended learning that allows a variety of teaching and learning approaches. The general goal of blended learning scenarios should be finding a practicable balance between teacher-centred instruction and learnercentred construction, guidance and autonomy. This balance needs to be based on the particular objectives of the curriculum and the needs of the students. It has to be pointed out that the theoretical views and practical approaches resulting from a more instruction-oriented versus a more construction-oriented approach mustn't be regarded as mutually exclusive but as complementary. The challenge lies in gradually shifting the balance from more traditional approaches to learning and teaching towards more progressive, process-oriented ways.

\section{Practical Constructivist and Collaborative APPROACHES TO LEARNING AND TEACHING IN TECHNiCAl PART-Time STUdies AT CAMPUS PinKAFELD}

The constructivist-based didactic approaches and their corresponding teaching methods and learning strategies pursued at Campus Pinkafeld are supposed to successfully help part-time students acquire the relevant skills and competences for their future field of work. The students are offered practical and future oriented training to become an energy and environmental manager, energy technician or building engineer and manager. The aim of the Bachelor's and Master's degree programmes is to provide a practice-oriented training of students with an academically sound, problem-conscious and resultoriented approach in the field of energy and environmental management. Students are offered a balanced combination of theory and a thorough practical training approach. Graduates are able to not only identify energy and environmental problems but also to develop efficient interdisciplinary solutions which are both sustainable and economically compatible. Through the encouragement of academic reflection, methodologically sound work, application-oriented project assignments and internships in Austria or abroad, students are trained to develop holistic approaches and solutions.

\section{A. Constructivist Pedagogy and Competency-based Curriculum}

Compared to technical full-time studies, the design of part-time degree programmes in the key area of study energy and environmental management at Campus 
Pinkafeld implies two major organisational differences. First, courses only take place at weekends, i. e. Friday afternoons and Saturdays, and second, the number of $\mathrm{f} 2 \mathrm{f}$ courses is reduced to a reasonable minimum which allows students to pursue a degree alongside their regular jobs as well as to participate in the programmes although they don't live and/or work within easy travel distance. The reduction of the required hours of attendance at the campus results in a range of combinations of on-site and off-campus study modules, which fosters a variety of constructivist-based blended learning scenarios. At Campus Pinkafeld blended learning means learning activities based on a combination of traditional f2f with computer and web-based online learning settings (including e-learning), multiple theories of learning and pedagogic approaches (cf. behaviourism, cognitivism and constructivism) and a variety of media and tools employed in f2f and online learning environments, including traditional print materials as well as all kinds of technology-based materials.

In order to support constructivist and collaborative teaching and learning processes and to create effective blended learning scenarios, the learning management system provided at Campus Pinkafeld is accessible to all part-time students and lecturers. The system currently used is ILIAS, an open source learning management system for developing and realizing web-based e-learning which includes tools for cooperative working and communication and the efficient creation of courses and course materials. In each course the platform is used to provide a course outline, lecturer contact information, downloadable lecture notes and material, project guidelines and material complementary to courses such as additional readings and web-resources. The synchronous and asynchronous communication tools are used to support students with questions, homework problems etc. Since the platform is not supposed to be a mere add-on to learning that provides additional study material and communication tools, there are advances to gradually implement blended learning settings and constructivist ideas in various courses and to eventually fully incorporate web-based blended learning scenarios into the curriculum. In order to fully utilize the advantages of the learning management system workshops to help lecturers use the online platform in a meaningful and efficient way are held on a regular basis and all lecturers of the technical part-time degree programmes are encouraged to work together and share resources and best practice examples in an open manner.

As far as curriculum design is concerned, all part-time degree programmes are broken down into individual modules, each comprising a series of individual courses which are again split into a series of f2f and online modules. All of these modules are defined in terms of learning outcomes, i. e. what students should be able to do after completing the module. These definitions are supposed to help students understand what they are expected to achieve in terms of knowledge, understanding, skills and competencies at the end of each module. Furthermore, this modular system allows for some flexibility in the choice and combination of modules studied. In this way students are offered individual training routes when it comes to learning foreign languages and choosing technical compulsory elective modules which best reflect their individual needs and interests.

\section{B. Web-based Constructivist and Collaborative Learning Environments}

The overall goal of implementing new pedagogic theories and designing new didactic models at Campus Pinkafeld is to shift learning from a rather teacher-centred to a more student-centred approach that focuses on webbased constructivist and collaborative learning environments. Examples of some of these environments that can be found throughout the different courses and the technical degree programmes are briefly summarized in the list below:

- Online discussion boards are generally used to pose and answer questions, to discuss ideas, suggestions, solutions, course content, recent performance, homework assignments and current issues. In some courses students have to give mutual feedback on various assignments (mainly written work) according to a checklist provided by the lecturer. The use of discussion boards increases both studentstudent and student-teacher discussion and helps develop critical thinking skills.

- Online workspaces/virtual learning environments are provided to work on, present and discuss the results of web-based collaborative learning activities such as simulations, web-quests, case studies and research projects. Through such activities students develop higher level thinking and social interaction skills, explore alternate problem solutions, learn to view problems from multiple perspectives, learn "how" to think, rather than "what" to think, and build selfconfidence in their own abilities.

- Workplace learning in bachelor's degree programmes is supported by online activities (documentation assignments, online questionnaires) and communication (e-mailing, discussion boards, chats etc.). Internships to provide hands-on experience in energy businesses and the building engineering industry are compulsory for those students participating in part-time degree programmes who haven't worked in a related business so far or don't have any work experience at all.

- Field trips to energy providers, power plants, sewage treatment plants etc. allow students to put the concepts and ideas discussed in various courses in a real-world context. They work on questions and problems to prepare for the trip and present and discuss their results in the online workspaces provided. They also have to work on assignments after the trip to ensure learning transfer.

- Online tools to create online libraries, glossaries, questions for self-check tests to measure learning progress etc. can be used by both lecturers and students. The collaborative assignments are set as part of the coursework.

- In some courses online study material and work assignments are provided that allow to create individual learning paths. Students choose their own 
skill level and development track and are coached and assessed by a lecturer.

- There are online workspaces (protected areas) particularly designed for students and lecturers of all degree programmes in the key area of study energy and environmental management which allow communication, exchange of information and collaboration.

\section{Example Courses}

Four of these approaches shall be illustrated in more detail. The first one concerns English language classes, which are compulsory for all students of all degree programmes. English language skills of first semester students vary considerably from rather poor to nearly perfect. The reasons for these differences are to be found in individual school histories, the use of English as a working language and temporary employment or other stays abroad. It therefore was necessary to offer an optional course to support students with rather poor command of the English language to brush up and improve their speaking, listening, reading and writing skills. As f2f time is rather limited in part-time degree programmes, it is used in conversation classes to improve their spoken English. In order to practice the remaining skills an additional online course was designed and implemented. In this online course students have to work on a series of grammar and vocabulary modules which include a variety of reading, listening and writing tasks. As all students participating in the course have their own starting points from which they process the new learning content and relate it to their previous knowledge, they first have to get a rough idea of the contents of the course and then create a sequence of learning steps which they discuss with their coach. After agreeing on individual learning paths they have to study the theory and do the exercises. Each module provides printable material as well as online exercises, so it is up to the students to choose activities according to their preferred learning style. The written assignments are to be sent to the coach who gives feedback and assesses the students' learning progress. As the number of students participating in the course is rather limited the online course mainly focuses on individual learning assignments but also provides web-based learning activities for pair and group work. Students are also invited to create a grammar forum. Each time they have a grammar question they start a new discussion thread and give it a title (e. g. word order, adverb/adjective etc.). In this way the forum can be used as a kind of grammar reference book for all students.

Another example of a constructivist teaching approach focuses on project-based learning that emphasises interdisciplinary views on technical and economic issues. The students practice an array of skills from marketing, project and cost management to (English) presentation skills. Second year students are asked to work in pairs to introduce a new product or service into an existing market in the field of energy and environmental management. They have to conceive, plan and conduct the whole project themselves. First they have to come up with a marketing strategy and then develop a marketing plan and write a corresponding project plan with goals, tasks, milestones, budget, risk assessment etc. Before they start to work on their project they have to attend a kick-off meeting. During the project phase they are offered online workspaces with a variety of tools and provided online support (discussion boards, e-mailing, and chat). After completing the project they have to present their results to their fellow students both online and in a f2f session. Each pair of students gets teacher and student feedback not only on the content of their project but also presentation techniques and English language skills (as part of the presentation has to be given in English). This projectbased learning assignment is supposed to make students see the interdisciplinary nature of these tasks. Besides, students have the freedom to choose different strategies and approaches and thus become more engaged in the learning process. They gain valuable experience in setting their own goals and standards of excellence. The project is part of a blended learning concept consisting of some f2f marketing sessions before the kick-off of the project and some project management and presentation technique lessons during the project phase. English language classes are to be attended regularly all over the course of the project and provide students with useful presentation language.

A third example concerns case studies which have to be solved in teams of four to five students. After a kick-off meeting at the beginning of a term they work on their cases over the period of at least three months. Each team is provided with an online workspace that allows them to communicate with students and coaches, exchange information and provide material. The final projects are presented online in a project folder and f2f in a presentation meeting where they receive teacher and student feedback. The learning process induced by these tasks is based on complex problems encountered in the field of sustainable energy systems which are a stimulus for organizing learned and integrating new information in ways that will ensure its recall and application to future problems. The case studies are designed to challenge learners to develop effective problem-solving and critical thinking skills as they are forced to scrutinize problems from multiple perspectives (technical, economic, legal, and social). They also have to identify what they need to learn to better understand the problem and how to resolve it. By sharing, interacting and collaborating, the final product manifests the rich individual and group learning processes of the students.

People who want to be admitted to the Bachelor's degree programme Energy and Environmental Management but have not achieved the general matriculation level required, are offered a specially designed course to prepare students for entry into higher education. It is mainly aimed at people who want to improve their career prospects but don't have the necessary qualifications to join a university degree programme. The prerequisites to be admitted to this preparation course are relevant vocational qualifications such as a completed apprenticeship or a vocational secondary school-leaving certificate. The subjects of the two semester course cover mathematics, physics, English and German. Examinations are to be taken at the end of the course to get proof of meeting the matriculation standard. The course is an ideal way to get back into the study habit by introducing the students not only to the subjects but also the study habits required to succeed in an academic setting. It provides the underpinning knowledge and skills needed to be admitted to a Bachelor's degree programme and aims at developing the study and 
autonomous learning skills necessary for higher education. The overall course design is based on a blended learning concept in which one third of the teaching hours are replaced by online learning. Constructivist-oriented teaching and learning approaches are found throughout the course to prepare students for their studies at Campus Pinkafeld in the best possible way.

\section{CONCLUSION}

There are many benefits of web-based constructivist learning and teaching approaches such as the active involvement of students in the learning process, the acquisition of transferable knowledge, enriched course materials and the promotion of social and communication skills. However, not all lecturers and students are convinced of a constructivist framework from the start. The cause lies in the old educational system which emphasizes content memorization and individual student performance. Particularly older lecturers and students have hardly been exposed to web-based constructivist and collaborative teaching and learning techniques. They haven't been trained in constructivist and collaborative methods and so the lecture method is still the method of their choice. Lecturers might fear loss of control in the lecture if they give more responsibility to the students for their learning progress. It also takes a great deal of selfconfidence in oneself and one's students to transfer the responsibility of learning to the student. Some might also fear the loss of content coverage because allowing group interaction often takes longer than giving simple lectures. There are also concerns when it comes to assessing students' efforts. They are unfamiliar with continuous assessment techniques or how to assess group efforts. Another cause for concern lies in the students' possible resistance to collaborative learning techniques. Students also have to become comfortable with new methods, so they might express concerns and doubts in the beginning. As they are not likely to change their attitudes to learning from one lecture to another, they also need to be trained in constructivist and collaborative learning techniques.

Irrespective of the suggested benefits and possible reasons why lecturers and students sometimes resist constructivist learning and teaching approaches it can be concluded that the organisational changes involved in technical part-time studies at Campus Pinkafeld and along with these the exploration of web-based blended learning settings have helped to promote lifelong learning opportunities in Burgenland. According to the European Union's policy, lifelong learning is defined as 'all learning activity undertaken throughout life, with the aim of improving knowledge, skills and competence, within a personal, civic, social and/or employment-related perspective' [6] and is therefore about valuing all forms of learning (formal, non-formal and informal) in all possible learning settings, from pre-school to post-retirement ages. In this context all part-time degree programmes offered at Campus Pinkafeld enable students to participate more actively in social, academic and economic life and to take control of their future professional lives in which professional, responsible and result-oriented actions in the areas of energy and the environment are becoming more and more important as our society needs environmentally sound and financially acceptable concepts to tackle energy and environmental problems.

Students' motives for studying are primarily their desire to improve their career prospects, but they are also motivated by intellectual factors, such as an interest in the subject. The main reason for choosing a part-time study, however, is that many adult students simply can not afford to give up their job or they are constrained by work and/or family commitments. Hence, part-time studies have to be fitted around these realities and/or other demands of their daily lives. As part-time students make up an increasing proportion of students at Campus Pinkafeld, organizational patterns and academic practices need to be reviewed and more flexibility allowed into the system. The timing of the courses has to suit the students' existing commitments and new course delivery patterns and pedagogic approaches, using web-based learning environments, need to be implemented. The potential for synergies between part-time and full-time studies also needs to be considered. So far, organizational and pedagogic designs as well as technology and tools have been made available, teaching staff and students, however, still need quite a deal of support to bring about a real change in learning culture at Campus Pinkafeld, a change that leaves behind traditional notions of learning and teaching, embracing open, technology-aided learning environments in higher technical education.

\section{REFERENCES}

[1] J. S. Bell and R. Mitchell, "Competency-based versus Traditional Cohort-based Technical Education: A Comparison of Students' Perceptions”, [online], Journal of Career and Technical Education, Vol 17, No 1, 2001, http://scholar.lib.vt.edu/ejournals/JCTE/ v17n1/bell.html.

[2] P. E. Doolittle and W. G. Camp, "Constructivism: The Career and Technical Education Perspective”, [online], Journal of Vocational and Technical Education, Vol 16, No 1, 1999, http://scholar.lib.vt.edu/ejournals/JVTE/v16n1/doolittle.html.

[3] J. S. Bell and R. Mitchell, loc. cit.

[4] P. E. Doolittle and W. G. Camp, loc. cit.

[5] G. Reinmann-Rothmeier, Didaktische Innovation durch Blended Learning. Leitlinien anhand eines Beispiels aus der Hochschule, Huber Psychologie Praxis, Lernen mit neuen Medien, Verlag Hans Huber, Bern, 2003, pp. 31ff.

[6] European Commission, "Lifelong Learning”, [online], Official Website, 2008, http://ec.europa.eu/education/policies/lll/life/ what_islll_en.html.

\section{AUTHOR}

A. Kelz is with the University of Applied Sciences Burgenland, Campus Pinkafeld, Austria (e-mail: andrea.kelz@fh-burgenland.at).

This article was modified from a presentation at the International Conference of Interactive Computer Aided Learning ICL2008, September 24 - 26, 2008 in Villach, Austria. Manuscript received 13 January 2008. Published as submitted by the author. 